\title{
Comparison of blood folate levels among pregnant Chinese women in areas with high and low prevalence of neural tube defects
}

\author{
Aiguo Ren*, Le Zhang, Ling Hao, Zhiwen Li, Yihua Tian and Zhu Li \\ Institute of Reproductive and Child Health, Peking University Health Science Center, \\ 38 Xueyuan Road, Haidian District, Beiijing 100083, People's Republic of China
}

Submitted 8 November 2005: Accepted 13 June 2006: First published online 26 March 2007

\begin{abstract}
Objective: To characterise plasma and red-blood-cell (RBC) folate status among pregnant women in an area with an extremely high prevalence of neural tube defects, and to compare them with those of women from a low prevalence area.

Design: A cross-sectional survey conducted in 2003.

Setting: One county and one city from each of the high prevalence area and the low prevalence area in China.

Subjects: Five hundred and sixty-two women in their first trimester of pregnancy in the high prevalence area and 695 pregnant women in the low prevalence area.

Results: Women in the high prevalence area had less than half the plasma and RBC folate concentrations (12.2 and $440.0 \mathrm{nmoll}^{-1}$, respectively) of women in the low prevalence area (33.5 and $910.4 \mathrm{nmol}^{-1}$, respectively). In the high prevalence area, $40 \%$ of rural women were deficient in RBC folate and $50 \%$ were deficient in plasma folate; $20 \%$ of urban women were deficient in RBC folate and 30\% deficient in plasma folate. In contrast, only $4 \%$ (RBC folate) and $6 \%$ (plasma folate) of rural women, and $2 \%$ (RBC folate) and 1\% (plasma folate) of urban women, were folate-deficient in the low prevalence area. Less than $10 \%$ of rural and about $26 \%$ of urban women in the high prevalence area took folic acid periconceptionally, compared with 70\% and 60\% of women in the low prevalence area.

Conclusions: Blood folate deficiency is highly prevalent among pregnant women in an area of China with a very high prevalence of neural tube defects.
\end{abstract}

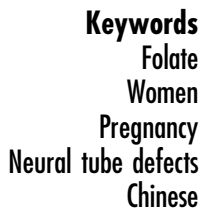

Although China overall has one of the highest birth prevalence rates of neural tube defects (NTDs) in the world $^{1}$, rates within the country are quite variable. Southern regions of the country, such as Jiangsu Province near Shanghai, have rates comparable to those in many developed countries (1996 NTD rate in Jiangsu: 0.83/1000 births ${ }^{2}$ ). However, the northern provinces of China have much higher birth prevalence NTD rates ${ }^{3,4}$. Our previous work showed that northern women of childbearing age had lower blood folate levels than those in the south ${ }^{5}$, and our subsequent large-scale community intervention programme demonstrated that periconceptional use of $400 \mu \mathrm{g}$ folic acid daily reduced the risk of NTDs by $85 \%$ in the north and $40 \%$ in the south ${ }^{6}$. In 1993, the Chinese Ministry of Health began to promote folic acid supplementation among women of childbearing age to prevent NTDs ${ }^{7}$. Yet despite years of nationwide promotion of folic acid, the birth prevalence of NTDs remains high in some provinces of the country. In particular, in Shanxi, one of the northern provinces, the prevalence of NTDs, as ascertained from provincial hospital-based surveillance of pregnancy outcomes from 28 weeks' gestation to 7 days of life, was 9.7/1000 births in 1996 and was as high as 4.5/ 1000 births in $2002^{8}$. To our knowledge, these rates remain among the highest in the world.

Low intake of dietary folate has been implicated as the underlying cause of the extremely high birth prevalence of NTDs in the north ${ }^{9}$, but there have been no reports of blood folate levels in pregnant women. Understanding blood folate status is an important first step towards effective intervention, particularly given the long history of recommendations for consumption of folic acid supplements before and during early pregnancy.

The purpose of the present study was to assess blood folate levels during early pregnancy among women from a high prevalence province in the north and to compare them with those of women from a low prevalence province in the south.

\section{Methods}

\section{Sample size determination}

The study was conducted between 1 December 2002 and 30 April 2004 in one rural county (Pingding) and one city 
(Taiyuan) in Shanxi Province, a high prevalence area, and one rural county (Wuxi-xinqu) and one city (Wuxi) in Wuxi City, a low prevalence area in Jangsu Province. The present analysis is limited to data collected in 2003 because a change in marriage registration policy beginning on 1 October 2003 likely resulted in a decrease in folic acid uptake in the study area.

To detect a minimum difference of $5 \mathrm{nmoll}^{-1}$ (standard deviation $20 \mathrm{nmoll}^{-1}$ ) in plasma folate concentration between rural and urban subgroups, with a $P$-value of 0.05 or less and a power of $80 \%$, we determined that 336 women would be required in each area. After allowing for possible blood sample loss of 10\% due to haemolysis during blood collection, we decided to recruit 360 rural women and 360 urban women in each of the high and low prevalence areas. We divided this number evenly by 12 months, yielding 30 rural and 30 urban women per month in both the high prevalence area and the low prevalence area.

\section{Subject enrolment}

In each province, the first 30 consecutive pregnant women who came to the rural and the urban maternal and child health centre for prenatal care before completing 16 weeks of pregnancy, determined from the date of the last menstrual period (LMP), were invited to participate each month. Women with chronic liver and renal diseases were excluded.

At enrolment, height without shoes and body weight in light clothing were measured to the nearest $0.1 \mathrm{~cm}$ and $0.1 \mathrm{~kg}$, respectively. At that time, a trained interviewer administered a questionnaire to collect information on sociodemographic and personal characteristics that might be related to blood folate status. Included among these variables were current age, educational level $(<10$ th grade or $\geq 10$ th grade), gravidity (primigravida or multigravida), current cigarette smoking (yes or no), alcohol drinking (defined as having at least one drink of alcohol per week; yes or no), periconceptional use of folic acid or multivitamins containing folic acid (yes or no) and frequencies of vegetable and fruit consumption. Body mass index (BMI) was calculated as weight $(\mathrm{kg}) /[\text { height }(\mathrm{m})]^{2}$.

\section{Blood sample collection and laboratory analyses}

At the time of enrolment a 4-ml non-fasting blood sample was collected by venepuncture. Blood samples were drawn into $\mathrm{K}_{3}$ EDTA-containing Vacutainer tubes (Becton Dickinson) and centrifuged within $1 \mathrm{~h}$ of collection. Plasma and red blood cells were separated and frozen at $-20^{\circ} \mathrm{C}$. All specimens were transported on dry ice to our laboratory and stored at $-70^{\circ} \mathrm{C}$. Red blood cells were hydrolysed with chicken pancreas conjugase prior to analyses. The redblood-cell (RBC) folate extract was stored at $-70^{\circ} \mathrm{C}$ until assay. Plasma and $\mathrm{RBC}$ folate concentrations were determined by microbiological assay using 96-well microtitre plates, as described by O'Broin and Kelleher ${ }^{10}$. The intra- and inter-assay coefficients of variation were $<9 \%$ across the full range of folate concentrations. RBC folate data were corrected using haemoglobin concentration to calculate the folate/haemoglobin ratio (ng folate/g haemoglobin) and the data were then converted to RBC folate concentrations $\left(\mathrm{nmoll}^{-1}\right)$. Details of the laboratory procedures can be found elsewhere ${ }^{11}$. Folate deficiency was defined as either $<10.5 \mathrm{nmol}^{-1}$ for plasma folate ${ }^{12}$ or $<363 \mathrm{nmoll}^{-1}$ for RBC folate ${ }^{13}$.

\section{Statistical analysis}

Since the distributions of plasma and RBC folate concentrations were positively skewed, natural logarithmic transformations were used to normalise the distributions, and geometric means as well as their 95\% confidence intervals (CI) were calculated. Student's $t$-test was used to compare means, and the Pearson chi-square test was used to compare categorical variables. Analysis of covariance was conducted to compare means adjusted for appropriate potential confounding variables. Multivariate logistic regression analysis was used to identify risk factors for plasma and RBC folate deficiency. The data were analysed with SPSS for Windows version 11.5 (SPSS Inc.). All $P$-values were two-sided and statistical significance was set at $P \leq 0.05$.

\section{Ethical approval}

The study protocol was reviewed and approved by the Institutional Review Board of Peking University Health Science Center. All invited participants provided written informed consent.

\section{Results}

From 1 January 2003 to 31 December 2003, a total of 1284 pregnant women were recruited. Among these, 27 were excluded, either because the date of the LMP was not known $(n=11)$ or because gestational age exceeded 16 weeks ( $n=16$ ), leaving 1257 (98\%) women for analysis. Women in the high prevalence area were older than those in the low prevalence area (Table 1), and rural women in the high prevalence area had higher mean BMI than rural women in the low prevalence area. Mean gestational age at the time of the study was lower for women in the high prevalence area than for women in the low prevalence area, in both urban and rural settings. Women in the high prevalence area were much more likely than women in the low prevalence area to have less than 10th grade education; this was most notable for rural women in the high prevalence area, where almost three-quarters had less than 10th grade education. In addition, more than half of women in the low prevalence area were having their first pregnancy, whereas only about one-third of those in the high prevalence area were pregnant for the first time. Cigarette smoking and alcohol drinking were not prevalent among women in either the high or low prevalence area, but were more common in the high 
Table 1 Characteristics of pregnant Chinese women, 2003

\begin{tabular}{|c|c|c|c|c|}
\hline \multirow[b]{2}{*}{ Characteristic } & \multicolumn{2}{|c|}{ High prevalence area } & \multicolumn{2}{|c|}{ Low prevalence area } \\
\hline & Rural & Urban & Rural & Urban \\
\hline Number of women & 358 & 204 & 327 & 368 \\
\hline Age (years), mean \pm SD & $28.8 \pm 5.2^{\star \star \star}$ & $26.9 \pm 3.2^{\star \star}$ & $23.7 \pm 2.0$ & $26.2 \pm 2.7$ \\
\hline $\mathrm{BMI}\left(\mathrm{kg} \mathrm{m}^{-2}\right)$, mean $\pm \mathrm{SD}$ & $22.3 \pm 3.0^{\star \star \star}$ & $20.9 \pm 2.6$ & $20.2 \pm 2.4$ & $20.5 \pm 2.3$ \\
\hline Gestational age (weeks), mean $\pm S D$ & $8.2 \pm 2.4^{\star \star \star}$ & $8.0 \pm 2.2^{\star \star \star}$ & $10.4 \pm 2.4$ & $9.5 \pm 2.5$ \\
\hline Less than 10 th grade education (\%) & $72.5^{\star \star \star}$ & $19.1^{\star \star \star}$ & 26.7 & 8.4 \\
\hline Primigravida (\%) & $26.5^{\star \star \star}$ & $39.2^{\star \star}$ & 66.5 & 51.9 \\
\hline Current cigarette smoking (\%) & $3.1^{*}$ & 2.0 & 0.9 & 0.3 \\
\hline Current alcohol drinking (\%) & $6.2^{\star \star}$ & $10.3^{\star \star \star}$ & 1.5 & 1.6 \\
\hline Periconceptional folic acid úse (\%) & $9.2^{\star \star \star}$ & $26.0^{\star \star \star}$ & 70.7 & 62.2 \\
\hline
\end{tabular}

SD - standard deviation; BMI - body mass index.

Significantly different from rural or urban women in the low prevalence area: ${ }^{\star} P<0.05,{ }^{\star \star} P<0.01,{ }^{\star \star \star} P<0.001$.

prevalence area. Less than $10 \%$ of rural and about $26 \%$ of urban women in the high prevalence area reported that they had taken folic acid or multivitamins containing folic acid before conception or during early pregnancy, compared with $71 \%$ of rural women and $62 \%$ of urban women in the low prevalence area.

Both urban and rural women in the high prevalence area had significantly lower plasma and RBC folate concentrations than did women in the low prevalence area (Table 2). Plasma folate concentrations were 2.5 to 2.7 times higher, and RBC folate concentrations were 1.8 to 2.2 times higher, among women in the low prevalence area than among women in the high prevalence area. In the high prevalence area, about $44 \%$ of women were deficient in plasma folate and 35\% in RBC folate, compared with about $3 \%$ of women being deficient in both plasma and $\mathrm{RBC}$ folate in the low prevalence area.

When stratified by periconceptional folic acid use and adjusted for age, BMI, gestational weeks, education $(<10$ th grade, $\geq 10$ th grade), gravidity (primigravida, multigravida), cigarette smoking (yes/no) and alcohol drinking (yes/no), the differences in plasma and RBC folate concentrations between the high and low prevalence areas remained (Table 3). Regardless of whether women lived in a high or low prevalence area, women who took folic acid had twofold higher plasma folate concentrations, and about 40\% higher RBC folate concentrations, than women who did not take folic acid. In the low prevalence area, only a few women who took folic acid had plasma and RBC folate deficiency. In contrast, in the high prevalence area, 15\% and 19\% of women who took folic acid had plasma folate and RBC folate deficiency, respectively. This was more pronounced in the high prevalence rural area, where $30 \%$ of periconceptional folic acid users had plasma folate deficiency and 28\% had RBC folate deficiency.

Multivariate unconditional logistic analysis showed that having a higher BMI, and residing in the high prevalence area and in the rural community were associated with an increased risk, and periconceptional folic acid use was associated with a decreased risk, for both plasma and RBC folate deficiency (Table 4). Women living in the high prevalence area had 10-fold higher risk of having both plasma folate deficiency and RBC folate deficiency compared with women living in the low prevalence area. In addition, cigarette smoking was associated with an elevated risk of plasma folate deficiency. Age, gestational weeks, educational level, gravidity, cigarette smoking and alcohol drinking were not associated with the risk of RBC folate deficiency.

When we analysed the high prevalence area and the low prevalence area separately, periconceptional folic

Table 2 Plasma and RBC folate levels in pregnant Chinese women by region and residence, 2003

\begin{tabular}{|c|c|c|c|c|c|c|c|c|}
\hline & \multicolumn{4}{|c|}{ Plasma folate } & \multicolumn{4}{|c|}{ RBC folate } \\
\hline & $n$ & $\begin{array}{c}\text { Geometric } \\
\text { mean }\left(\mathrm{nmolI} \mathrm{I}^{-1}\right)\end{array}$ & $95 \% \mathrm{Cl}$ & $\begin{array}{l}\text { Deficient } \\
\text { (\%)† }\end{array}$ & $n$ & $\begin{array}{c}\text { Geometric } \\
\text { mean }\left(\mathrm{nmolI} \mathrm{I}^{-1}\right)\end{array}$ & $95 \% \mathrm{Cl}$ & $\begin{array}{c}\text { Deficient } \\
(\%) \dagger\end{array}$ \\
\hline \multicolumn{9}{|c|}{ High prevalence area } \\
\hline Total & 557 & $12.2^{\star \star \star}$ & $11.5-12.9$ & $43.8^{\star \star \star}$ & 554 & $440.0^{\star \star \star}$ & $418.1-463.1$ & $35.0^{\star \star \star}$ \\
\hline Rural & 356 & $10.8^{\star \star \star}$ & $10.1-11.7$ & $49.7^{\star \star \star}$ & 354 & $401.1^{\star \star \star}$ & $377.4-426.2$ & $43.2^{\star \star \star}$ \\
\hline Urban & 201 & $14.9^{\star \star \star}$ & $13.6-16.4$ & $33.3^{\star \star \star}$ & 200 & $518.4^{\star \star \star}$ & $474.6-566.3$ & $20.5^{\star \star \star}$ \\
\hline \multicolumn{9}{|c|}{ Low prevalence area } \\
\hline Total & 673 & 33.5 & $31.9-35.2$ & 3.4 & 667 & 910.4 & $878.6-943.4$ & 3.0 \\
\hline Rural & 318 & 29.6 & $27.5-31.9$ & 5.7 & 317 & 885.9 & $839.2-935.3$ & 4.1 \\
\hline Urban & 355 & 37.4 & $35.1-39.8$ & 1.4 & 350 & 933.2 & $890.4-978.1$ & 2.0 \\
\hline
\end{tabular}

RBC - red blood cell; $\mathrm{Cl}$ - confidence interval.

†Plasma folate $<10.5 \mathrm{nmoll}^{-1}$, RBC folate $<363 \mathrm{nmolI}^{-1}$.

Significantly different compared with the means or rates in the low prevalence area: ${ }^{\star \star \star} P<0.001$. 
Table 3 Blood folate levels in pregnant Chinese women by region, residence and periconceptional folic acid use, 2003

\begin{tabular}{|c|c|c|c|c|c|c|c|c|}
\hline & \multicolumn{4}{|c|}{ Periconceptional folic acid use } & \multicolumn{4}{|c|}{ No periconceptional folic acid use } \\
\hline & $n$ & $\begin{array}{c}\text { Geometric } \\
\text { mean }\left(\mathrm{nmol} \mathrm{I}^{-1}\right)\end{array}$ & $95 \% \mathrm{Cl}$ & $\begin{array}{l}\text { Deficient } \\
\text { (\%)† }\end{array}$ & $n$ & $\begin{array}{c}\text { Geometric } \\
\text { mean }\left(\mathrm{nmoll} \mathrm{I}^{-1}\right)\end{array}$ & $95 \% \mathrm{Cl}$ & $\begin{array}{c}\text { Deficient } \\
(\%) \dagger\end{array}$ \\
\hline \multicolumn{9}{|c|}{ Plasma folate } \\
\hline \multicolumn{9}{|c|}{ High prevalence area } \\
\hline Totalł & 85 & $23.5^{\star \star \star}$ & $20.3-27.2$ & $15.3^{\star \star \star}$ & 471 & $10.9^{\star \star \star}$ & $10.4-11.6$ & $48.9^{\star \star \star}$ \\
\hline Rural§ & 33 & $20.5^{\star \star}$ & $15.2-27.7$ & $30.3^{\star \star \star}$ & 322 & $10.2^{\star \star \star}$ & $9.6-10.9$ & $51.7^{\star \star \star}$ \\
\hline Urban§ & 52 & $27.5^{\star \star \star}$ & $23.6-32.0$ & $5.8^{* \star}$ & 149 & $12.2^{\star * *}$ & $11.1-13.3$ & $43.0^{* \star *}$ \\
\hline \multicolumn{9}{|c|}{ Low prevalence area } \\
\hline Totalł & 443 & 42.9 & $30.3-44.5$ & 1.1 & 226 & 20.3 & $18.7-22.1$ & 7.9 \\
\hline Rural§ & 220 & 35.8 & $32.2-39.9$ & 2.3 & 94 & 18.0 & $15.6-20.7$ & 13.8 \\
\hline Urban§ & 222 & 49.6 & $46.3-53.3$ & 0.0 & 132 & 23.2 & $21.1-25.6$ & 3.8 \\
\hline \multirow{2}{*}{\multicolumn{9}{|c|}{$\begin{array}{l}R B C \text { folate } \\
\text { High prevalence area }\end{array}$}} \\
\hline & & & & & & & & \\
\hline Total $\ddagger$ & 83 & $609.9^{\star \star \star}$ & $542.4-685.9$ & $19.3^{\star \star \star}$ & 470 & $415.2^{\star \star \star}$ & $394.5-437.0$ & $37.8^{\star \star \star}$ \\
\hline Rural§ & 32 & $496.9^{\star \star \star}$ & $400.0-617.3$ & $28.1^{\star \star \star}$ & 321 & $388.0^{\star \star \star}$ & $364.1-413.3$ & $44.7^{\star \star \star}$ \\
\hline Urban§ & 51 & $715.9^{\star \star \star}$ & $623.6-821.9$ & $13.7^{\star \star \star}$ & 149 & $462.6^{\star \star \star}$ & $424.7-503.9$ & $22.8^{\star \star \star}$ \\
\hline \multicolumn{9}{|c|}{ Low prevalence area } \\
\hline Totalł & 438 & 1042.1 & $992.9-1093.8$ & 1.8 & 226 & 699.8 & $646.9-757.0$ & 5.3 \\
\hline Rural§ & 220 & 997.5 & $926.6-1073.8$ & 2.7 & 93 & 694.8 & $608.4-793.3$ & 7.5 \\
\hline Urban§ & 217 & 1077.0 & $1010.5-1147.9$ & 0.9 & 133 & 733.8 & $669.8-804.0$ & 3.8 \\
\hline
\end{tabular}

RBC - red blood cell; $\mathrm{Cl}$ - confidence interval.

$\dagger$ Plasma folate $<10.5 \mathrm{nmoll}^{-1}$, RBC folate $<363 \mathrm{nmolI}^{-1}$.

$\ddagger$ Means were adjusted for age, body mass index, gestational weeks, education $(<10$ th grade/ $\geq 10$ th grade), gravidity (primigravida/multigravida), smoking (yes/no), drinking (yes/no) and residence (rural/urban).

$\S$ Means were adjusted for age, body mass index, gestational weeks, education, gravidity, drinking and smoking.

Significantly different compared with the means or rates in the low prevalence area: ${ }^{\star \star} P<0.01,{ }^{\star \star \star} P<0.001$.

acid use was protective against both plasma folate deficiency and RBC folate deficiency. While residing in a rural community was associated with an elevated risk of both plasma folate deficiency and RBC folate deficiency in the high prevalence area, it was associated only with an increased likelihood of plasma folate deficiency in the low prevalence area. In addition, BMI and cigarette smoking were associated with elevated risk of plasma folate deficiency in the high prevalence area (data not shown).

\section{Discussion}

We found that women's mean plasma and RBC folate concentrations during early pregnancy in an area with a high prevalence of NTDs were less than half those of women in an area with a low NTD prevalence. In the high prevalence area, $44 \%$ of women were deficient in plasma folate and $35 \%$ in RBC folate. Fewer than 10\% of rural women and $26 \%$ of urban women in the high prevalence area reported having taken folic acid supplements before and during early pregnancy. In the high prevalence rural community, even among those women who took folic acid, about 30\% had blood folate deficiency. To our knowledge, this is the first study to characterise the blood folate status and periconceptional folic acid use among women during early pregnancy in an area with an extremely high birth prevalence of NTDs, and to compare these measures with those of women in a low prevalence area in China.

The differences in blood folate levels and folic acid supplementation between the high and low prevalence area and between the rural and urban area are consistent with the distribution of NTDs. In a population-based birth defects surveillance system, we found an NTD birth prevalence of $7.4 / 1000$ births ( $\geq 20$ weeks' gestational age to 7 days of life) in the high prevalence area and

Table $4 \mathrm{OR}$ and $95 \% \mathrm{Cl}$ of blood folate deficiency in pregnant Chinese women, 2003

\begin{tabular}{|c|c|c|c|c|c|c|}
\hline \multirow[b]{2}{*}{ Variable } & \multicolumn{3}{|c|}{ Plasma folate deficiency } & \multicolumn{3}{|c|}{ RBC folate deficiency } \\
\hline & OR & $95 \% \mathrm{Cl}$ & $P$-value & OR & $95 \% \mathrm{Cl}$ & $P$-value \\
\hline BMl‡ & 1.07 & $1.01-1.14$ & 0.022 & 1.06 & $1.00-1.13$ & 0.043 \\
\hline Living in high prevalence area & 9.92 & $6.11-16.13$ & $<0.001$ & 9.88 & $5.79-16.85$ & $<0.001$ \\
\hline Rural resident & 1.75 & $1.23-2.49$ & 0.002 & 2.46 & $1.68-3.59$ & $<0.001$ \\
\hline Periconceptional folic acid use & 0.17 & $0.10-0.30$ & $<0.001$ & 0.41 & $0.25-0.69$ & 0.001 \\
\hline Current cigarette smoking & 3.46 & $1.06-11.34$ & 0.040 & - & - & \\
\hline
\end{tabular}

OR - odds ratio; $\mathrm{Cl}$ - confidence interval; RBC - red blood cell; BMI - body mass index.

$\dagger$ Mutually adjusted by an unconditional logistic model.

$\ddagger \mathrm{BMI}$ as a continuous variable. 
$0.46 / 1000$ births in the low prevalence area ${ }^{14}$. In the high prevalence area, the birth prevalence of NTDs was 14.4/ 1000 births in the rural area, compared with 7.3/1000 births in the urban area ${ }^{15}$.

The very low blood folate levels for women in the high prevalence area may reflect, in part, low folate intake from dietary sources 9 . Women living in areas of northern China that include the high prevalence area, which has a relatively harsh, arid climate and a shorter growing season than the low prevalence area, have been reported to have reduced intake of folate-rich foods ${ }^{11}$. This is supported by a preliminary analysis of selected food frequencies, which indicated that only $18 \%$ of rural and $39 \%$ of urban pregnant women consumed fruit $\geq 6$ times a week in the high prevalence area, compared with $51 \%$ and $71 \%$ for rural and urban women, respectively, in the low prevalence area. Consumption of fresh vegetables had a similar pattern (data not shown).

Folic acid use was a strong predictor of blood folate concentrations. In contrast to the relatively high percentage of periconceptional folic acid use in the low prevalence area, very few women took folic acid in the high prevalence area. The large differences in periconceptional folic acid use between the high and low prevalence areas may be attributed to the differences in the proportion of women who received counselling at a premarital health assessment. At the time this survey was conducted, a premarital health assessment was required of all couples planning to marry. The assessment consisted of a physical examination, laboratory tests and counselling. At that time, women would receive information concerning the benefit of folic acid in preventing NTDs, and would be advised to take folic acid supplements before and during early pregnancy. While virtually all couples received premarital health assessment in the low prevalence province in $2003^{16}$, only $57 \%$ of young couples in Taiyuan City $^{17}$ and less than $20 \%$ in Pingding County (Ruiqin Zhai, personal communication, Maternal and Child Health Center, Pingding County, Shanxi Province) did so in the high prevalence area. In addition, women have to pay around \$US 1.5 per month for the folic acid supplements. This is perceived by local health-care providers as one of the barriers to folic acid use, especially for those who live in the northern rural area where socioeconomic development is relatively slow.

Although the majority of the women in the present study are of Han ethnicity, the predominant ethnic group in China (99.1\% in the northern high prevalence province, $99.4 \%$ in the southern low prevalence province), genetic differences between northern and southern Han Chinese have been reported ${ }^{18}$. For example, several studies have shown that northern Han populations have a higher frequency of mutation in the gene encoding methylenetetrahydrofolate reductase enzyme (MTHFR C677T) ${ }^{19,20}$, and also possibly in another gene encoding reduced folate carrier (RFC1 A80G) $)^{21}$, compared with southern Han populations. Since the mutated form of MTHFR has been shown to be associated with decreased plasma and RBC folate concentrations ${ }^{22}$, the low levels of blood folate observed in the high prevalence area may be attributable, in part, to the higher prevalence of the MTHFR C677T mutation in the population. The role of RFC1 is not clear since the association between RFC1 polymorphism and blood folate concentrations is unknown.

In our study, current smoking predicted plasma folate deficiency (odds ratio $=3.5$ ). This finding is consistent with several other recent reports ${ }^{23-26}$ indicating that pregnant women who smoke have lower blood folate levels than those who do not smoke. Although only a very small proportion of pregnant women in this study reported smoking compared with other populations ${ }^{27,28}$, it is important to consider smoking as a potential contributor to low blood folate levels in this population since the smoking rate among pregnant women in the high prevalence area, who had very low blood folate levels, was higher than that of women in the low prevalence area. Programmes targeted at the high prevalence population to raise awareness about the importance of periconceptional folic acid supplementation should also incorporate a smoking cessation component.

Periconceptional folic acid supplementation can substantially raise a woman's blood folate concentration ${ }^{29,30}$, and can reduce the risk of NTDs by $85 \%$ in northern China ${ }^{6}$ and by $50-70 \%$ in other countries ${ }^{31,32}$. In 1992, the US Public Health Service recommended that all women of childbearing age who are capable of becoming pregnant should consume $400 \mu \mathrm{g}$ of folic acid per day for the purpose of reducing their risk of having a pregnancy affected by an $\mathrm{NTD}^{33}$. In 1993, the Chinese Ministry of Health began to promote folic acid supplementation among women of childbearing age around the country. Daily supplementation with $400 \mu \mathrm{g}$ folic acid is encouraged for all women who plan to have a baby ${ }^{34}$. Although nearly 10 years have passed since the nationwide promotion began, and a lot of effort has been made both at national and provincial levels, periconceptional supplementation with folic acid is not widely implemented in the country. Recently, Botto et al. ${ }^{35}$ analysed 10-year NTD incidence data from 13 birth defects registries, correlated it with folic acid recommendations or policies, and found no apparent decline in the incidence of NTDs following the release of the recommendations, suggesting that the recommendations may not be fully implemented. Our results from the high prevalence area support this observation.

One strength of our study is that blood folate concentrations were measured among women during early pregnancy, since a woman's risk of having a pregnancy affected by an NTD is associated with her blood folate levels during early pregnancy ${ }^{36}$. One limitation of the present study was the impact of the SARS (severe acute respiratory syndrome) epidemic in Taiyuan, the capital city of Shanxi Province, in the spring of 2003. 
The epidemic resulted in cessation of virtually all nonemergency health-care visits and most research activities. Therefore, we were unable to recruit women during May and June, and from August to October, the numbers of women recruited were quite low in the city. If blood folate concentration fluctuates substantially over time, this problem could cause either overestimation or underestimation of folate levels for urban women in the high prevalence area. However, when we restricted the analyses to January to April, July, November and December, in which around 20 or more women were recruited in the high prevalence city, the results did not change substantially, and the conclusion remained the same.

In conclusion, we found that, in an area with an extremely high prevalence of NTDs in China, blood folate deficiency was highly prevalent among women during early pregnancy. Most women of childbearing age in this area did not take periconceptional folic acid despite years of nationwide promotion of folic acid for NTD prevention. Efforts are needed to deliver public health messages about the importance of folic acid in the prevention of NTDs, as well as lifestyle activities that may increase risk, such as cigarette smoking, to women in all segments of the community. All women who are planning a pregnancy, particularly those living in areas with limited access to folate-rich foods, should have affordable access to folic acid supplements. Other means of delivering folic acid should be investigated, including fortification of the food supply. Additional studies to further elucidate the role of genetic determinants of NTD risk, as well as the contribution of lifestyle and behavioural factors such as cigarette smoking, are warranted.

\section{Acknowledgements}

We thank Drs Zhanying Guo, Yongsheng Jin, Ruiqin Zhai, Feiran Zhang and Yinzhong Li for their contributions to data collection. This work was supported by the Tenth Key Technologies Research and Development Program, Ministry of Science and Technology, People's Republic of China (grant no. 2002BA709B11).

\section{References}

1 Moore CA, Li S, Li Z, Hong SX, Gu HQ, Berry RJ, et al. Elevated rates of severe neural tube defects in a highprevalence area in northern China. American Journal of Medical Genetics 1997; 73: 113-8.

2 Li Z, Zheng JC, Li S. Annual Report on Perinatal Health Care and Birth Defects Surveillance 1996. Beijing: Beijing Medical University Press, 2002.

3 Cheng N, Bai Y, Hu X, Pei H, Li Y, Zhang W, et al. A base-line survey on birth defects in Gansu province, West China. Annals of Tropical Paediatrics 2003; 23: 25-9.

4 Lian ZH, Yang HY, Li Z. Neural tube defects in BeijingTianjin area of China. Urban-rural distribution and some other epidemiological characteristics. Journal of Epidemiology and Community Health 1987; 41: 259-62.

5 Li Z, Liu X, Chen Y, Chang $\mathrm{H}$, Chen L, Tang Y, et al. Difference in prevalence and seasonal variations of folate deficiencies among pre-marital women from high and low risk areas of neural tube defects (in Chinese). Zhongguo Yousheng Youyu Zazhi 1996; 1: 1-4.

6 Berry RJ, Li Z, Erickson JD, Li S, Moore CA, Wang H, et al. Prevention of neural-tube defects with folic acid in China. China-US Collaborative Project for Neural Tube Defect Prevention. New England Journal of Medicine 1999; 341: 1485-90.

7 Department of Science, Technology and Education, Ministry of Health. Collection of 10-year 100 Marketable Scientific Research Findings (in Chinese). Beijing: Hongqi Press, 1996; $58-60$.

8 Zhang X, Wang L. Analysis of birth defects surveillance, 1996-2002 (in Chinese). Zhongguo Fuyou Baojian 2004; 19: 93-4.

9 Melnick M, Marazita ML. Neural tube defects, methylenetetrahydrofolate reductase mutation, and north/south dietary differences in China. Journal of Craniofacial Genetics and Developmental Biology 1998; 18: 233-5.

10 O'Broin S, Kelleher B. Microbiological assay on microtitre plates of folate in serum and red cells. Journal of Clinical Pathology 1992; 45: 344-7.

11 Hao L, Ma J, Stampfer MJ, Ren A, Tian Y, Tang Y, et al. Geographical, seasonal and gender differences in folate status among Chinese adults. Journal of Nutrition 2003; 133: $3630-5$.

12 Hao L, Zheng JC, Tian YH, Fan DW, Li Z. Comparative study of the detection of plasma folate with microbial assay and radioimmunoassay (in Chinese). Beijing Daxue Xuebao 2004; 36: 210-4

13 Choumenkovitch SF, Jacques PF, Nadeau MR, Wilson PW, Rosenberg IH, Selhub J. Folic acid fortification increases red blood cell folate concentrations in the Framingham study. Journal of Nutrition 2001; 131: 3277-80.

14 Li ZW, Ren A, Zhang L, Guo ZY, Li S, Ye RW, et al. Prevalence of major external birth defects in high and low risk areas in China, 2003 (in Chinese). Zhonghua Liuxingbingxue Zazhi 2005; 26: 252-7.

15 Li ZW, Ren A, Zhang L, Jin YS, Zheng JC, Hong SX, et al. Epidemiology of major external birth defects in high risk areas of Shanxi Province, China (2003) (in Chinese). Zhongguo Youshang Yu Yichuan Zazhi 2005; 13: 87-9.

16 Zhang F, Ma F, Wang J, Zhu H, Ye A. A survey on the current reproductive health status among migrant women, Wuxi City (in Chinese). Zhongguo Fuyou Baojian 2002; 17: 228-9.

17 Hong H, Zhao G, Sun A. Analysis of premarital health assessment data, 1996-2002 (in Chinese). Zhongguo Shengyu Jiankang Zazhi 2005; 16: 221-2.

18 Chu JY, Huang W, Kuang SQ, Wang JM, Xu JJ, Chu ZT, et al. Genetic relationship of populations in China. Proceedings of the National Academy of Sciences of the USA 1998; 95: 11763-8.

19 Wilcken B, Bamforth F, Li Z, Zhu H, Ritvanen A, Renlund M, et al. Geographical and ethnic variation of the $677 \mathrm{C} \rightarrow \mathrm{T}$ allele of 5,10-methylenetetrahydrofolate reductase (MTHFR): findings from over 7000 newborns from 16 areas world wide. Journal of Medical Genetics 2003; 40: 619-25.

20 Zhu J, Ren A, Hao L, Pei L, Liu J, Zhu H, et al. Variable contribution of the MTHFR C677T polymorphism to nonsyndromic cleft lip and palate risk in China. American Journal of Medical Genetics 2006; 140A: 551-7.

21 Pei LJ, Ren AG, Zhu HP, Hao L, Zhao WR, Li Z. Study on reduced folate carrier gene (RFC1) polymorphism in the southern and northern Chinese population (in Chinese). Zhonghua Liuxingbingxue Zazhi 2004; 25: 499-502.

22 Molloy AM, Daly S, Mills JL, Kirke PN, Whitehead AS, Ramsbottom D, et al. Thermolabile variant of 5,10methylenetetrahydrofolate reductase associated with low red-cell folates: implications for folate intake recommendations. Lancet 1997; 349: 1591-3. 
23 Stark KD, Pawlosky RJ, Beblo S, Murthy M, Flanagan VP, Janisse $\mathrm{J}$, et al. Status of plasma folate after folic acid fortification of the food supply in pregnant African American women and the influences of diet, smoking, and alcohol consumption. American Journal of Clinical Nutrition 2005; 81: 669-77.

24 Ozerol E, Ozerol I, Gokdeniz R, Temel I, Akyol O. Effect of smoking on serum concentrations of total homocysteine, folate, vitamin $\mathrm{B}_{12}$, and nitric oxide in pregnancy: a preliminary study. Fetal Diagnosis and Therapy 2004; 19 $145-8$.

25 van Wersch JW, Janssens Y, Zandvoort JA. Folic acid, vitamin $\mathrm{B}\left({ }_{12}\right)$, and homocysteine in smoking and non-smoking pregnant women. European Journal of Obstetrics, Gynecology and Reproductive Biology 2002; 103: 18-21.

26 Pagan K, Hou J, Goldenberg RL, Cliver SP, Tamura T. Effect of smoking on serum concentrations of total homocysteine and $\mathrm{B}$ vitamins in mid-pregnancy. Clinica Chimica Acta 2001; 306: 103-9.

27 Ananth CV, Kirby RS, Kinzler WL. Divergent trends in maternal cigarette smoking during pregnancy: United States 1990-99. Paediatric and Perinatal Epidemiology 2005; 19 $19-26$.

28 Spencer K, Bindra R, Cacho AM, Nicolaides KH. The impact of correcting for smoking status when screening for chromosomal anomalies using maternal serum biochemistry and fetal nuchal translucency thickness in the first trimester of pregnancy. Prenatal Diagnosis 2004; 24: 169-73.

29 Norsworthy B, Skeaff CM, Adank C, Green TJ. Effects of once-a-week or daily folic acid supplementation on red blood cell folate concentrations in women. European Journal Clinical Nutrition 2004; 58: 548-54.

30 Brouwer IA, van Dusseldorp M, Thomas CM, Duran M, Hautvast JG, Eskes TK, et al. Low-dose folic acid supplementation decreases plasma homocysteine concentrations: a randomized trial. American Journal Clinical Nutrition 1999; 69: 99-104.

31 Czeizel AE, Dudas I. Prevention of the first occurrence of neural-tube defects by periconceptional vitamin supplementation. New England Journal of Medicine 1992; 327: 1832-5.

32 MRC Vitamin Study Research Group. Prevention of neural tube defects: results of the Medical Research Council Vitamin Study. Lancet 1991; 338: 131-7.

33 Centers for Disease Control and Prevention. Recommendations for the use of folic acid to reduce the number of cases of spina bifida and other neural tube defects. Morbidity and Mortality Weekly Report. Recommendations and Reports 1992; 41: 1-7.

34 Li Z, Yan R, Qin X, Peng R, Qian Y, Qu C, et al. The necessity of promoting maternal folic acid supplementation to prevent neural tube defects in China (in Chinese). Zhongguo Yousheng Youyu Zazhi 1994; 5: 33-7.

35 Botto LD, Lisi A, Robert-Gnansia E, Erickson JD, Vollset SE, Mastroiacovo $\mathrm{P}$, et al. International retrospective cohort study of neural tube defects in relation to folic acid recommendations: are the recommendations working? British Medical Journal 2005; 330: 571

36 Daly LE, Kirke PN, Molloy A, Weir DG, Scott JM. Folate levels and neural tube defects. Implications for prevention. Journal of American Medical Association 1995; 274: 1698-702. 